\title{
Mengukur Tingkat Kesiapsiagaan Anggota PKK RT. 05 Desa Banyuraden dalam Menghadapi Bencana Gempa
}

\author{
Mandiyo Priyo1, Restu Faizah ${ }^{2 *}$ \\ 1,2Program Studi Teknik Sipil, Fakultas Teknik, Universitas Muhammadiyah Yogyakarta \\ *e-mail: restu.faizah@umy.ac.id
}

\begin{abstract}
Women as agents of change are expected to have an active role in disaster risk reduction (DRR) activities, mainly to defend themselves and their families from the effects of disasters. This dedication activity is a preparedness level assessment of the members of PKK RT. 05 RW. 08, Banyuraden village, Gamping Sleman DIY. It is an academic involvement to support the village program in realization a disaster-resilient village (Destana) and to solute the partner's problem. The assessment method uses a framework developed by the Indonesian Institute of Sciences (LIPI) in collaboration with The United Nations Educational, Scientific and Cultural Organization (UNESCO) and International Strategy for Disaster Reduction (ISDR) in 2006. There are three stages of assessment, i.e. a survey for collecting data using a questionnaire, analyzing the preparedness index, and determining the preparedness level. Because the activities were carried out during the Covid-19 pandemic, the questionnaire was conducted using Google forms to implement the physical distancing program. This dedication activity found a description that the members of PKK RT. 05. RW. 08 Banyuraden village, Gamping Sleman DIY has a moderate of preparedness rate, with an index of $62.07 \%$. The aspect of disaster knowledge was classified as good, but the emergency response plan and resource mobilization are not yet. The implementation of the Destana program in the Banyuraden village, Sleman district, especially in RT.05 RW.08 might be aligned with the results of this dedication activity. Further dedication activities can also be carried out, such as drafting emergency response plans and organizing preparedness training for families to improve the community preparedness of RT. 05 RW. 08, Banyuraden, Gamping Sleman DIY.
\end{abstract}

Keywords: preparedness level, women role, earthquake disaster, family preparedness

\begin{abstract}
Abstrak
Perempuan sebagai agen perubahan, diharapkan dapat berperan aktif dalam kegiatan pengurangan risiko bencana (PRB), terutama agar dapat mempertahankan diri dan keluarganya dari dampak bencana. Kegiatan pengabdian ini berupa penilaian tingkat kesiapsiagaan anggota PKK RT. 05 RW. 08 Banyuraden Gamping Sleman DIY. Kegiatan ini merupakan bentuk keterlibatan akademisi dalam mendukung program desa Banyuraden untuk mewujudkan Desa Tangguh Bencana (Destana) dan memberikan solusi pada permasalahan mitra. Metode penilaian merujuk pada framework yang dikembangkan oleh Lembaga Ilmu Pengetahuan Indonesia (LIPI) bekerja sama dengan The United Nations Educational, Scientific and Cultural Organization (UNESCO) dan International Strategy for Disaster Reduction (ISDR) pada tahun 2006. Tahapan penilaian terdiri dari survei pengambilan data dengan kuosioner, analisis indeks kesiapsiagaan, dan penentuan tingkat kesiapsiagaan. Dikarenakan kegiatan dilaksanakan pada masa pandemic Covid-19, maka kuosioner dilakukan menggunakan google form untuk menerapkan program physical distancing. Kegiatan pengabdian ini memberikan gambaran bahwa tingkat kesiapsiagaan anggota PKK RT. 05. RW. 08 Banyuraden Gamping Sleman DIY dalam menghadapi bencana gempa berada pada tingkat sedang, dengan Indeks Kesiapsiagaan 62,07\%. Aspek pengetahuan terhadap bencana sudah tergolong bagus, namun belum terdapat rencana tanggap darurat dan mobilisasi sumber daya yang baik. Oleh karena itu pelaksanaan program Destana di Desa Banyuraden Gamping Sleman, terutama di RT.05 RW.08 sebaiknya diselaraskan dengan hasil kegiatan pengabdian ini. Kegiatan pengabdian lanjutan juga dapat dilakukan, seperti kegiatan penyusunan rencana tanggap darurat dan penyelenggaraan pelatihan-pelatihan kesiapsiagaan pada keluarga untuk meningkatkan kesiapsiagaan warga RT. 05 RW. 08 desa Banyuraden Gamping Sleman DIY.
\end{abstract}

Kata kunci: tingkat kesiapsiagaan, peran perempuan, bencana gempa, kesiapsiagaan keluarga.

\section{PENDAHULUAN}

Bentuk peningkatan peran perempuan dalam pengurangan risiko bencana diantaranya berupa pendidikan kesiapsiagaan terhadap bencana dan keselamatan, yang merupakan prioritas utama untuk antisipasi bencana. Pengintegrasian informasi tentang resiko bencana ke dalam kehidupan sehari-hari merupakan langkah yang diharapkan mampu mengurangi resiko bencana 
yang tidak diinginkan. Perempuan seharusnya dikenalkan dengan lingkungan tempat tinggal mereka agar mampu memahami dinamika alam. Pemahaman terhadap dinamika alam ini menjadi prasyarat utama untuk penyelamatan terhadap resiko bencana. Guna mencapai ini diharapkan peran perempuan dapat dilibatkan dalam menghadapi bencana agar perempuan mampu mempertahankan diri dan keluarganya dari resiko bencana (Hastuti, 2017).

Fakta menunjukkan bahwa perempuan dan anak-anak berisiko meninggal 14x lebih besar daripada pria dewasa. Terbukti dalam peristiwa bencana gempabumi dan tsunami di Banda Aceh pada tahun 2004, 60 -70\% korban merupakan korban wanita, anak-anak dan lanjut usia, bahkan banyak ditemukan korban merupakan ibu yang meninggal bersama anaknya. Oleh karena itu Badan Nasional Penanggulangan Bencana (BNPB) mencanangkan program Gerakan Srikandi Siaga Bencana, dengan tagar "Jadikan perempuan sebagai guru kesiapsiagaan, jadikan rumah menjadi sekolahnya untuk menjadikan bangsa ini tangguh bencana". Beberapa program tersebut adalah memperluas akses informasi terkait kebencanaan, meningkatkan kapasitas perlindungan diri, mendidik keluarga siaga bencana, melindungi keluarga dari ancaman bencana, dan mendidik masyarakat di sekitarnya menjadi lebih waspada dan siaga bencana (Widjaya, 2019). Salah satu wadah bagi perempuan yang sangat efektif untuk meningkatkan perannya adalah organisasi PKK yang sudah ada hingga tingkat RT (Rukun Tetangga).

Pemberdayaan Kesejahteraan Keluarga, disingkat PKK, adalah organisasi kemasyarakatan yang memberdayakan wanita untuk turut berpartisipasi dalam pembangunan Indonesia. PKK memiliki 10 program pokok, yaitu penghayatan dan pengamalan pancasila, gotong royong, pangan, sandang, perumahan dan tatalaksana rumah tangga, pendidikan dan keterampilan, kesehatan, pengembangan kehidupan berkoperasi, kelestarian lingkungan hidup, dan perencanaan sehat (Wikipedia, 2019). Program-program pokok PKK tersebut sangat mendukung pelaksanaan tugas-tugas perempuan yang memiliki multi peran, baik peran dalam keluarga maupun di masyarakat. Oleh karena itu, peningkatkan peran serta perempuan dalam menghadapi bencana merupakan variabel penting untuk menekan kerugian sebagai dampak dari bencana.

Kegiatan pengabdian berupa penilaian tingkat kesiapsiagaan anggota PKK dalam menghadapi bencana gempa ini sangat selaras dengan program Gerakan Srikandi Siaga Bencana yang dicanangkan oleh BNPB. Dalam kegiatan ini, penilaian dilakukan pada ibu-ibu anggota PKK RT. 05 RW. 08 Banyuraden Gamping Sleman. Tujuan dari penilian adalah untuk mengetahui tingkat kesiapsiagaan ibu-ibu PKK dalam kegiatan pengurangan risiko bencana gempa. Hasil dari penilaian ini diharapkan dapat digunakan sebagai bahan rujukan dalam melakukan peningkatan peran wanita sebagai guru kesiapsiagaan bagi keluarga dan masyarakat. Hal ini juga selaras dengan tema Hari Kesiapsiagaan Bencana Nasional (HKBN) 2019 yaitu Siaga Bencana dimulai dari Keluarga.

Desa Banyuraden merupakan salah satu desa yang ditarget sebagai Desa Tangguh Bencana (Destana), sebagaimana dimaksud dalam Perka BNPB No. 1 Tahun 2012 Tentang Pedoman Umum Desa/Kalurahan Tangguh Bencana (BNPB, 2012). Luas wilayah Desa Banyuraden adalah $400 \mathrm{Ha}$ atau $4,00 \mathrm{Km}^{2}$, yang terdiri dari 8 wilayah pedukuhan, $22 \mathrm{RW}$ dan 78 RT (Admin, 2017). RT. 05 merupakan salah satu RT yang berada di wilayah RW. 08, Desa Banyuraden Kecamatan Gamping Kabupaten Sleman DIY. Untuk periode tahun 2016 - 2021, Ketua RT. 05 dijabat oleh Bapak Budi Kahono, dan Ketua RW. 08 adalah Bapak Sukamto. Adapun PKK RT. 05 merupakan wadah/organisasi wanita terbesar di lingkungan RT. 05 yang beranggotakan ibu-ibu (wanita yang sudah menikah) yang berusia muda hingga lanjut usia. PKK RT.05 diketuai oleh Ibu Tri Umarah yang sekaligus sebagai mitra dalam kegiatan pengabdian ini.

PKK RT. 05 RW. 08 Banyuraden Gamping Sleman sebagai mitra dalam pengabdian ini, memiliki anggota dengan beragam latar belakang pendidikan, yaitu lulusan SD hingga sarjana (S1/S2/S3), seperti ditunjukkan dalam Gambar 1. Dengan latar belakang pendidikan yang beragam tersebut, maka terdapat beragam profesi pula, seperti pedagang, pegawai, guru, dosen, wiraswasta, petani, dan ibu rumah tangga. Keberagaman tersebut dinilai dapat meningkatkan 
kerentanan ibu-ibu terhadap risiko bencana, dikarenakan tingkat pemahaman yang beragam. Selain itu, tingginya kerentanan juga diakibatkan oleh banyaknya ibu-ibu yang berusia lanjut, karena wanita lanjut usia dinyatakan sebagai kelompok rentan dalam Undang-Undang No. 24 Tahun 2007 (Presiden RI, 2007). Dengan kondisi ini, maka muncul permasalahan, yaitu mitra tidak mengetahui kondisi anggotanya dalam hal kesiapsiagaan terhadap bencana gempa. Hal ini mengakibatkan mitra mengalami kesulitan dalam menentukan bentuk kegiatan untuk mempersiapkan anggotanya sebagai wanita tangguh bencana. Oleh karena itu dilakukan kegiatan pengabdian ini untuk menjawab permasalahan mitra.
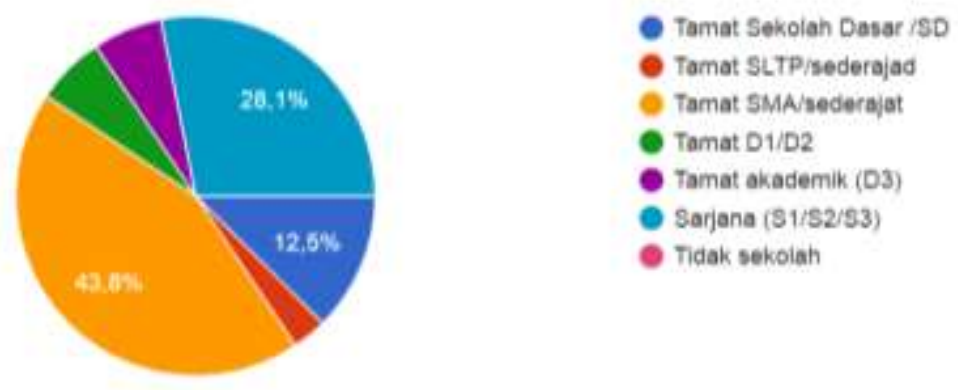

Gambar 1. Sebaran latar belakang pendidikan anggota PKK RT. 05 RW. 08 Banyuraden Gamping Sleman DIY

\section{METODE}

Penilaian tingkat kesiapsiagaan ibu-ibu anggota PKK RT. 05 ini menggunakan framework yang dikembangkan oleh Lembaga Ilmu Pengetahuan Indonesia (LIPI) bekerja sama dengan The United Nations Educational, Scientific and Cultural Organization (UNESCO) dan International Strategy for Disaster Reduction (ISDR) pada tahun 2006, seperti dijelaskan dalam Hidayat dkk., (2011). Tujuan umum kajian adalah untuk menilai tingkat kesiapsiagaan masyarakat dalam mengantisipasi bencana gempa, sedangkan tujuan khususnya adalah untuk meningkatkan kemampuan (kapasitas) masyarakat, menurunkan tingkat kerentanan dan agar lebih siap siaga ketika terjadi bencana gempa. Kegiatan penilaian meliputi tiga tahapan, yaitu survei pengambilan data menggunakan kuosioner, menentukan indeks kesiapsiagaan menggunakan metode skoring, dan penetapan tingkat kesiapsiagaan ke dalam tiga tingkatan, yaitu rendah, sedang dan tinggi. Karena kegiatan ini dilaksanakan pada masa pandemic Covid-19, maka pengambilan data dengan wawancara langsung atau tatap muka tidak bisa dilakukan. Survei dilakukan menggunakan kuosioner dalam bentuk google formulir yang disebar menggunakan sarana Whatsapp anggota PKK RT. 05.

Dalam penilaian ini diambil tiga parameter yang digunakan dalam mengkaji tingkat kesiapsiagaan masyarakat untuk mengantisipasi bencana, khususnya bencana gempa. Tiga parameter tersebut adalah pengetahuan dan sikap tentang risiko bencana gempa $\left(\mathrm{P}_{1}\right)$, rencana tanggap darurat $\left(\mathrm{P}_{2}\right)$, dan mobilisasi sumber daya $\left(\mathrm{P}_{3}\right)$. Semua parameter sudah diikuti dengan pertanyaan yang harus dijawab dengan cara memberi tanda centang pada jawaban yang dipilih (Hidayat dkk., 2011). Pada penelitian ini, tiap parameter memiliki indikator dengan jumlah yang berbeda-beda, seperti ditunjukkan dalam Tabel 1. Tiap indikator memiliki Indeks Indikator yang ditentukan berdasarkan Persamaan 1 . Setelah diperoleh Indeks Indikator, maka dapat ditentukan Indeks Parameter $\left(\mathrm{IP}_{1}, \mathrm{IP}_{2}\right.$, dan $\left.\mathrm{IP}_{3}\right)$ mengikuti Persamaan 2.

Tabel 1. Jumlah indikator pada tiap parameter

\begin{tabular}{cc}
\hline Parameter & Jumlah indikator \\
\hline $\mathrm{P}_{1}$ & 8 \\
$\mathrm{P}_{2}$ & 3 \\
$\mathrm{P}_{3}$ & 5 \\
\hline
\end{tabular}


Indeks Indikator $=\frac{\text { skor riil }}{\text { jumlah skor maksimum }} \times 100 \%$

Indeks Parameter $\left(I P_{1}, I P_{2}, I P_{3}\right)=\frac{\text { Jumlah Indeks Indikator }}{\text { jumlah Indikator }} \%$

Berdasarkan framework LIPI dengan sedikit penyesuaian, bobot dari tiap parameter adalah $56 \%, 29 \%$, dan $15 \%$ berturut-turut untuk $\mathrm{P}_{1}, \mathrm{P}_{2}$, dan $\mathrm{P}_{3}$. Selanjutnya, Indeks Kesiapsiagaan (IKS) yang merupakan gabungan dari Indeks semua parameter, dapat dihitung menggunakan Persamaan 3. Berdasarkan skor IKS ini, dapat ditentukan kategori tingkat kesiapsiagaan anggota PKK RT. 05 dalam menghadapi bencana gempa, sesuai dengan ketentuan dalam Tabel 2.

$I K S=\left(0,56 * I P_{1}+0,29 * I P_{2}+0,15 * I P_{3}\right) \%$

Tabel 2. Penentuan kategori tingkat kesiapsiagaan

\begin{tabular}{lll}
\hline Tingkat kesiapsiagaan & Skor & Kode (warna) \\
\hline Rendah & $0-33,3 \%$ & merah \\
Sedang & $33,4-66,6 \%$ & kuning \\
Tinggi & $66,7-100 \%$ & hijau \\
\hline
\end{tabular}

Setelah diketahuinya tingkat kesiapsiagaan anggota PKK RT. 05 berada dalam kategori rendah, sedang, atau tinggi, maka dapat dilakukan tindakan atau kegiatan yang tepat untuk meningkatkan peran serta wanita dalam pengurangan risiko bencana gempa di lingkungan masyarakat RT. 05, RW. 08 Banyuraden Gamping Slemnan DIY. Untuk melihat bagian mana yang perlu ditingkatkan, dapat memperhatikan nilai indeks tiap parameter.

\section{HASIL DAN PEMBAHASAN}

Kuosioner melalui google formulir diisi oleh 32 orang yang merupakan anggota PKK RT. 05 RW. 08 Banyuraden Gamping Sleman DIY, dengan karaketeristik responden ditunjukkan pada Tabel 3. Penilaian ini tidak memperhitungkan ibu-ibu yang termasuk pada kelompok usia manula yaitu di atas 60 tahun (Kemenkes RI, 2013). Hal itu dikarenakan wanita usia manula termasuk dalam kelompok usia rentan dan tidak termasuk objek dalam usaha peningkatan kesiapsiagaan. Seperti terlihat dalam Tabel 3, usia maksimum responden adalah 53 tahun dengan jenis pekerjaan terbanyak adalah sebagai Ibu Rumah Tangga.

Tabel 3. Karakteristik responden

\begin{tabular}{ll}
\hline Karakteristik & Keterangan \\
\hline Usia & $24-53$ tahun \\
Tingkat pendidikan & Tidak Sekolah - SMA 65,6\%, (D3/S1/S2/S3) 34,4\% \\
Pekerjaan & Ibu RT (37,6\%), PNS/ASN (3,1\%), karyawan $(12,5 \%)$, guru \\
& $(6,3 \%)$, dan pedagang $(15,6 \%)$ \\
Jumlah anak & $1-8$ orang \\
\hline
\end{tabular}

Hasil pengisian kuosioner meliputi parameter pengetahuan dan sikap tentang risiko bencana gempa $\left(\mathrm{P}_{1}\right)$, rencana tanggap darurat $\left(\mathrm{P}_{2}\right)$, dan mobilisasi sumber daya $\left(\mathrm{P}_{3}\right)$. Dalam Tabel 4 disebutkan indikator yang menjadi tema pertanyaan pada tiap parameter dan hasil perhitungan skornya. Pada setiap indikator mencakup pertanyaan yang jumlahnya sama dengan jumlah skor, sehingga dapat dihitung Indeks tiap indikator mengikuti Persamaan 1. Selanjutnya Indeks tiap Parameter dapat ditentukan dari jumlah Indeks Indikator dibagi dengan jumlah indikator (Persamaan 2). 
Tabel 4. Hasil pengisian kuosioner

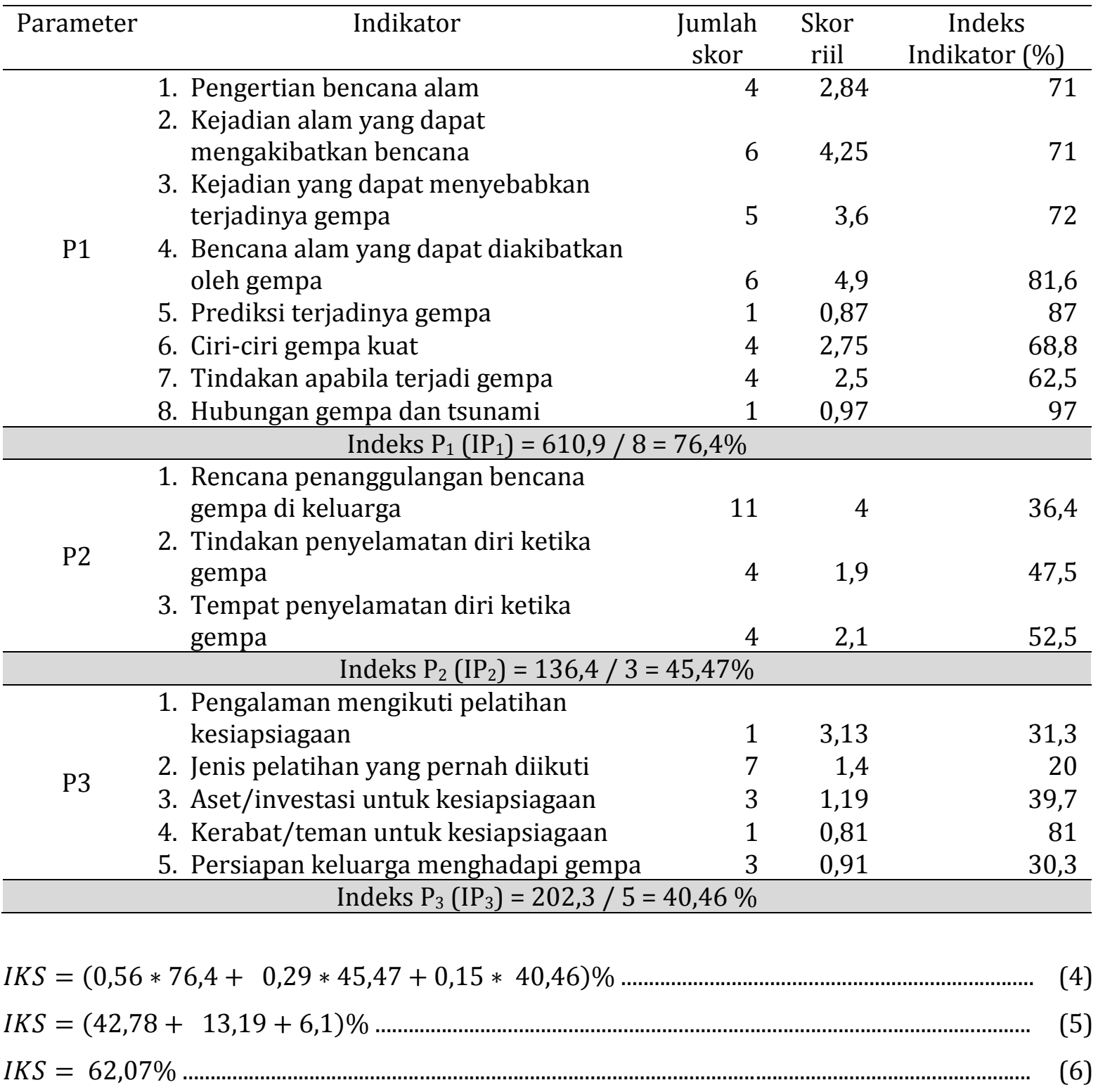

Setelah diketahui Indeks tiap parameter, maka dapat dihitung Indeks Kesiapsiagaan (IKS) mengikuti Persamaan 3. Hasil perhitungan IKS disebutkan dalam Persamaan 4-6, dengan nilai IKS yang diperoleh adalah sebesar 62,07\%. Apabila dikategorisasikan ke dalam tingkat kesiapsiagaan sesuai Tabel 2, maka Tingkat Kesiapsiagaan (IKS) anggota PKK RT. 05 RW. 08 Banyuraden Gamping Sleman DIY termasuk pada Tingkat Kesiapsiagaan Sedang dengan kode warna kuning.

Setelah dilakukan penilaian, diketahui tingkat kesiapsiagaan anggota PKK RT. 05 RW. 08 Banyuraden Gamping Sleman berada dalam tingkat kesiapsiagaan sedang. Hasil penilaian ini mengindikasikan bahwa masih perlu dilakukan kegiatan peningkatan keisapsiagaan pada anggota PKK RT. 05, agar bisa meningkat hingga memiliki tingkat kesiapsiagaan tinggi. Kegiatan yang efektif dilakukan dapat ditentukan berdasarkan hasil perhitungan indeks parameter. Nilai $\mathrm{IP}_{1}, \mathrm{IP}_{2}$, dan $\mathrm{IP}_{3}$ berturut-turut adalah 76,4\%, 45,47\%, dan 40,46\%. Apabila dikategorisasikan sesuai Tabel 2, maka $\mathrm{IP}_{1}$ memiliki tingkat tinggi, sedangkan $\mathrm{IP}_{2}$ dan $\mathrm{IP}_{3}$ memiliki tingkat sedang. Oleh karena itu, kegiatan peningkatan kesiapsiagaan hendaknya difokuskan pada peningkatan indeks parameter $\mathrm{IP}_{2}$ dan $\mathrm{IP}_{3}$, yaitu rencana tanggap darurat dan mobilisasi sumber daya.

Parameter pengetahuan dan sikap tentang risiko bencana gempa $\left(\mathrm{P}_{1}\right)$ dinilai sudah berada pada tingkat tinggi dikarenakan banyaknya sarana informasi dan pengetahuan tentang gempa yang dapat diakses oleh anggota PKK RT. 05. Dalam survei ini diperoleh data bahwa anggota PKK 
RT. 05 mendapatkan informasi tentang gempa dari berbagai media, seperti radio, TV, Koran/majalah/bulletin, HP, komputer, buku saku/poster/leaflet, bilboard, sosialisasi/seminar, saudara/kerabat, petugas pemerintah, LSM dan NGO (Gambar 2).

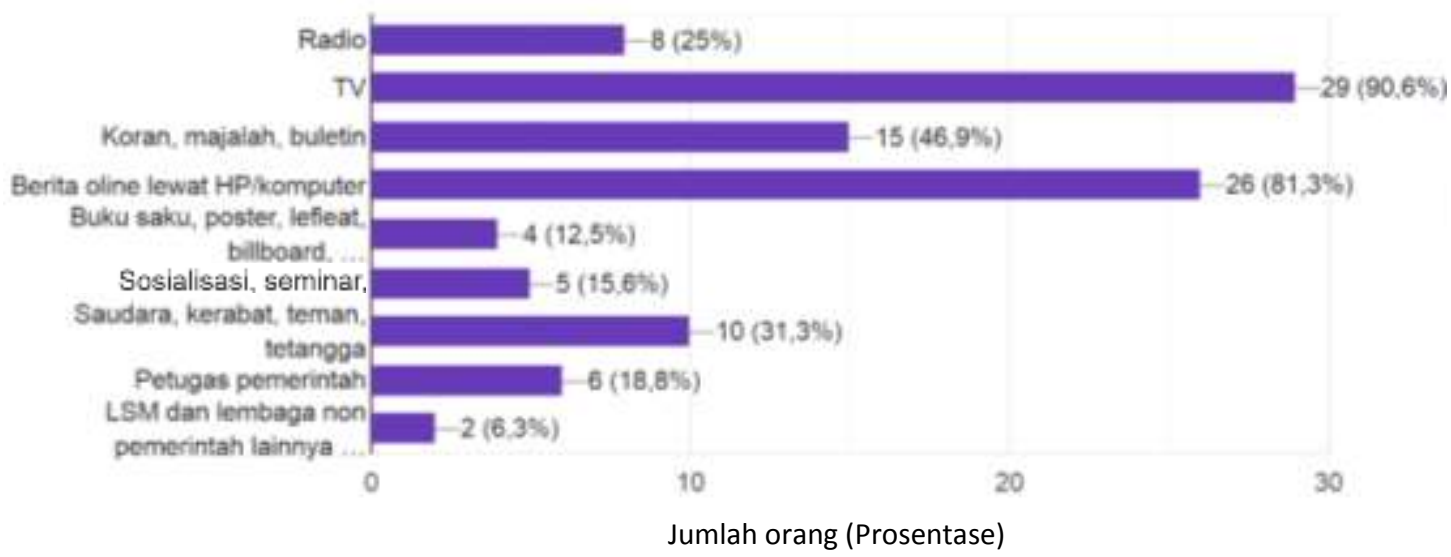

Gambar 2. Beberapa media sebagai sarana informasi gempa bagi anggota PKK RT. 05. RW. 08 Banyuraden Gamping Sleman DIY

Parameter rencana tanggap darurat $\left(\mathrm{P}_{2}\right)$ berada pada tingkat sedang, sehingga perlu ditingkatkan agar mencapai tingkat tinggi. Berdasarkan indeks indikatornya, maka kegiatan peningkatan pada indikator pertama sangat diperlukan, yaitu penyusunan rencana penanggulangan bencana gempa pada keluarga. Beberapa rencana tanggap darurat yang dapat ditingkatkan adalah:

- menyiapkan tindakan yang harus dilakukan oleh anggota keluarga jika terjadi gempa

- Menyepakati tempat pengungsian/evakuasi keluarga

- Menyiapkan peta dan rute pengungsian

- Menyiapkan makanan siap santap yang tahan lama seperlunya

- Menyiapkan kotak P3K

- Menyiapkan dokumen-dolumen penting dan bernilai

- Menyiapkan pakaian, uang tunai, dan kebutuhan khusus/darurat keluarga

- menyiapkan foto keluarga untuk dokumen.

Parameter mobilisasi sumber daya $\left(\mathrm{P}_{3}\right)$ juga perlu ditingkatkan karena masih berada pada tingkat sedang. Indeks Indikator yang masih rendah pada parameter ini adalah pengalaman anggota PKK RT. 05 dalam mengikuti pelatihan kesiapsiagaan. Hasil dari survei menunjukkan bahwa 68,8\% orang belum pernah mengikuti pelatihan kesiapsiagaan (Gambar 3). Pelatihan kesiapsiagaan sangat bermanfaat dalam meningkatkan kesiapsiagaan, sebagaimana dikatakan oleh Dharmawati dkk., (2020) bahwa dua faktor penting penentu suksesnya kegiatan adalah metoda dan media pembelajaran yang tepat. Oleh karena itu, perlu diberikan media pembelajaran berupa pelatihan-pelatihan kesiapsiagaan pada keluarga di wilayah RT. 05 RW. 08 Banyuraden Gamping Sleman, dengan tema yang lebih beragam, seperti pertolongan pertama, evakuasi korban, kepramukaan (tali temali, memasang tenda, dan membuat tandu), pengelolaan air bersih, dan pengolahan makanan.

Pada akhir kegiatan pengabdian ini, mitra menyampaikan harapannya agar dapat dilaksanakan kegiatan pengabdian lanjutan berupa penyusunan rencana penanggulangan bencana gempa pada keluarga dan penyelenggaraan pelatihan-pelatihan kesiapsiagaan pada keluarga di wilayah RT. 05 RW. 08 Banyuraden Gamping Sleman DIY. Kegiatan pengabdian lanjutan ini dapat dilaksanakan jika pandemic Covid-19 telah berakhir. 


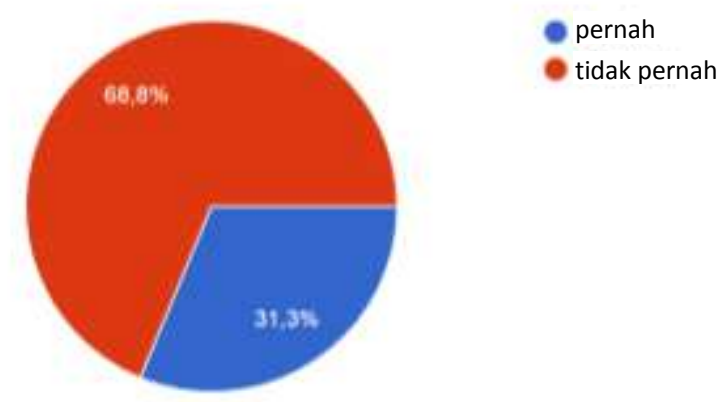

Gambar 3. Pengalaman anggota PKK RT. 05 dalam mengikuti pelatihan kesiapsiagaan

\section{KESIMPULAN}

Setelah dilakukan kegiatan pengabdian berupa penilaian tingkat kesiapsiagaan pada anggota PKK RT. 05. RW. 08 Banyuraden Gamping Sleman DIY, diperoleh beberapa kesimpulan sebagai berikut:

1. Anggota PKK RT. 05. RW. 08 Banyuraden Gamping Sleman DIY memiliki tingkat kesiapsiagaan tingkat sedang dalam menghadapi bencana gempa dengan Indeks Kesiapsiagaan 62,07\%.

2. Pengetahuan dan sikap tentang risiko bencana gempa tergolong tingkat tinggi, namun rencana tanggap darurat dan mobilisasi sumber daya masih kurang.

3. Diharapkan dapat dilakukan kegiatan pengabdian lanjutan berupa penyusunan rencana tanggap darurat dan dan peningkatan mobilisasi sumber daya dengan pelatihan-pelatihan kesiapsiagaan.

\section{UCAPAN TERIMA KASIH}

Penulis mengucapkan terima kasih kepada Universitas Muhammadiyah Yogyakarta, melalui Lembaga Penelitian, Publikasi, dan Pengabdian masyarakat (LP3M) yang telah memberi dukungan financial pada kegiatan ini.

\section{DAFTAR PUSTAKA}

Admin. (2017). Desa Banyuraden Kecamatan Gamping Kabupaten Sleman. Pemerintah Desa Banyuraden. https://banyuraden.slemankab.go.id/home/

BNPB. (2012). Peraturan Kepala Badan Penanggulangan Bencana (Perka BNPB) No. 1 Tahun 2012 Tentang Pedoman Umum Desa/Kalurahan Tangguh Bencana (p. 47).

Dharmawati, Lubis, I., \& Liza, R. (2020). Pembelajaran Berbasis Komputer Menggunakan Ms. Office 2019 Pada Siswa Di SMK Dwitunggal 1 Tanjung Morawa. Dinamisia, Jurnal Pengabdian Kepada Masyarakat, 4(1), 18-25. https://doi.org/DOI: https://doi.org/ 10.31849/dinamisia. v4i1.3751

Hastuti, H. (2017). Peran Perempuan dalam Menghadapi Bencana di Indonesia. Geomedia: Majalah Ilmiah dan Informasi Kegeografian, $14(2)$. https://doi.org/10.21831/gm.v14i2.13812

Hidayat, D., Widayatun, Hartana, P., Triyono, \& Kusumawati, T. (2011). Panduan Mengukur Tingkat Kesiapsiagaan Masyarakat dan Komunitas Sekolah. Pusat Penelitian Oseanografi LIPI.

Kemenkes RI. (2013). Gambaran Kesehatan Lanjut Usia di Indonesia. Buletin Lansia, 1, 32.

Presiden RI. (2007). Undang-undang No. 24 Tahun 2007 tentang Penanggulangan Bencana, UU No. 24 Th. 2007. 
Widjaya, W. (2019). Peran Perempuan dalam Membangun Ketangguhan Keluarga dan Masyarakat dalam Menghadapi Bencana [Paparan Deputi Bidang Kesiapsiagaan dan Pencegahan BNPB]. Peringatan Hari Kesiapsiagaan Bencana Nasional (HKBN) 2019, Graha Marinir Jakarta. https://siaga.bnpb.go.id/hkb/pocontent/uploads/4paparan_pak_deputi_bid_pencegahan_\%26_kesiapsiagaan_bnpb_talksh ow_grahamarinir06032019_dwp.pdf

Wikipedia. (2019). Pemberdayaan Kesejahteraan Keluarga. In Wikipedia bahasa Indonesia, ensiklopedia bebas. https://id.wikipedia.org/w/index.php?title=Pemberdayaan_Kesejahteraan_Keluarga\&oldi $\mathrm{d}=16323717$ 